\title{
IMPLEMENTASI DAN PERANCANGAN SISTEM KENDALI POSISI KETINGGIAN (ALTITUDE) QUADCOPTER BERBASIS ARDUINO UNO R3
}

\section{Implementation and Design Of Quadcopter Height Position (Altitude) Control System Based On Arduino Uno R3}

\author{
Ramli Zaenudin', I Made Budi Suksmadana', Giri Wahyu Wiriasto ${ }^{1}$ \\ 1) Jurusan Teknik Elektro, Fakultas Teknik, Universitas Mataram, Nusa Tenggara Barat, Indonesia \\ E-mail : zaenudinramli1993@gmail.com ${ }^{1}$; mdbudi@te.ftunram.ac.id $^{2}$; giriwahyuwiriasto@gmail.com $^{3}$
}

\begin{abstract}
ABSTRAK
Sebuah quadcopter dilengkapi dengan sensor ultrasonic HC-SR04 yang digunakan untuk membaca jarak yang bertujuan untuk menahan posisi ketinggian dari quadcopter. Pemanfaatan quadcopter tersebut pada bidang militer, multimedia, dan untuk penelitian yang tidak dapat dijangkau oleh manusia akan sangat tepat, khususnya untuk mengambil gambar dan video serta untuk pengambilan data penelitian. Quadcopter yang dirancang ditugaskan untuk mampu menahan posisi ketinggian tertentu sesuai dengan set-point yang diberikan. Pengambilan keputusan sistem, kontrol motor brushless sebagai aktuator, dan pengontrolan sensor-sensor dilakukan oleh mikrokontroler (atmega328). Pengendali kestabilan dan pengaturan posisi ketinggian quadcopter menggunakan kendali PID yang telah diterapkan kedalam sistem. Hasil dari penelitian ini adalah quadcopter mampu menahan posisi ketinggian sesuai dengan setpoint yang diberikan dan quadcopter mampu stabil di ketinggian tersebut dengan nilai $P=3.0, I$ $=0.02, D=0$, untuk menahan posisi ketinggian $10 \mathrm{~cm}$ rata-rata error-nya $0.42 \mathrm{~cm}$, posisi ketinggian $20 \mathrm{~cm}$ rata-rata error-nya $0.29 \mathrm{~cm}$ dan posisi ketinggian $30 \mathrm{~cm}$ rata-rata error-nya $0.32 \mathrm{~cm}$.
\end{abstract}

Kata kunci : quadcopter, sensor ultrasonic HC-SR04, IMU MPU6050, mikrokontroler, kendali PID

\section{ABSTRACT}

A quadcopter is equipped with an HC-SRO4 ultrasonic sensor which is used to read distances in order to hold the altitude position of the quadcopter. The use of the quadcopter in the military, multimedia, and for research that cannot be reached by humans would be very appropriate, especially for taking pictures and videos and for taking research data. The quadcopter is designed to be able to hold a certain height position in accordance with the setpoint given. System decision making, brushless motor control as an actuator, and control of the sensors is carried out by a microcontroller (atmega328). The stability control and height adjustment position of the quadcopter uses the PID control that has been applied to the system. The results of this study are the quadcopter is able to hold the height position in accordance with the set-point given and the quadcopter is able to be stable at that height with a value of $P=$ $3.0, I=0.02, D=0$, to hold the height position of $10 \mathrm{~cm}$ on the average error $0.42 \mathrm{~cm}$, the height position is $20 \mathrm{~cm}$, the average error is $0.29 \mathrm{~cm}$, and the height position is $30 \mathrm{~cm}$, the average error is $0.32 \mathrm{~cm}$.

Keywords: quadcopter, ultrasonic HC-SR04 sensor, IMU MPU6050, microcontroller, PID control

\section{PENDAHULUAN}

Teknologi UAV (Unmanned Aerial Vehicle) atau biasa disebut dengan quadcopter merupakan salah satu teknologi yang saat ini banyak diminati untuk diteliti dan dikembangkan oleh para peneliti pesawat tanpa awak. Quadcopter merupakan sebuah pesawat tanpa awak yang memiliki empat buah baling-baling (propeller) dan empat buah motor brushless sebagai aktuator. Penggunaan quadcopter saat ini sangat dibutuhkan baik itu dibidang multimedia, kesehatan, pendidikan, militer dan lain-lain. Pengaplikasian quadcopter pada bidangbidang tersebut digunakan untuk pengambilan data sebagai bahan penelitian, menjalankan misi yang beresiko tinggi, pengambilan gambar dan video yang tidak bisa dijangkau 
oleh manusia dan lain-lain.

Permasalahan yang sering dihadapi dalam pengoprasian quadcopter ini adalah masalah kesetabilan dari quadcopter ketika lepas landas, hover dan mendarat. Teknologi yang terdapat pada quadcopter menggunakan sinkronisasi antara keempat rotor yang telah dikonfigurasikan dalam bentuk frame $(x)$, dimana rotor depan kiri dan belakang kanan bergerak searah jarum jam (CW) sedangkan rotor depan kanan dan belakang kiri bergerak berlawanan arah jarum jam (CCW).

Kesetabilan pada quadcopter sangatlah penting dan harus dimiliki agar pemanfaatannya dapat maksimal. Penelitian pengendalian quadcopter agar dapat bergerak dengan stabil ini dilakukkan untuk mengimplementasikan dan menganalisis penerapan metode kendali PID untuk mengatur posisi ketinggian quadcopter agar tetap dalam keadaan stabil diudara dengan ketinggian tertentu.

Quadcopter memiliki 6 Degree of Freedom (DoF) dengan 12 state, 6 dari keluaran dari 12 state menentukan attitude dari quadcopter. Quadcopter memiliki 4 buah rotor sebagai penggerak baling-baling yang digunakan untuk menghasilkan gaya angkat. Baling-baling yang sering disebut dengan propeller yang dipasang bersama 4 buah brushless motor. Tipe dari quadcopter sendiri terdiri dari dua jenis, tipe $\mathrm{X}$ dan tipe + tergantung pada gerak laju pada quadcopter. Quadcopter memiliki frame dimana sebagai tulang tumpu pada koordinat $\mathrm{x}$ dan $\mathrm{y}$. (Pancev, 2013)

Gambar 1 merupakan sistem koordinat yang dipakai dalam rancangan. Manuver pada quadcopter dilakukkan dengan mengubah-ubah kecepatan putaran tiap motor. Sebagai ilustrasi pada gambar tersebut diperlihatkan arah dan kecepatan putaran masing-masing motor. Saat quadcopter melayang (hover) maka kecepatan putaran diatur sama untuk semua motor.

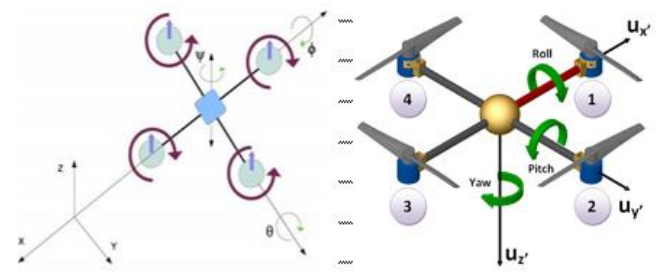

Gambar 1. Sistem koordinat rancangan quadcopter (Dharmawan, 2012)

Altitude quadcopter merupakan sikap orientasi pada titik tengah massa quadcopter.
Untuk menaikan atau menurunkan quadrotor secara vertikal, keempat rotor dikontrol dengan kecepatan yang sama. Terdapat tiga kritikal kontrol sistem pada dinamika penerbangan, yaitu roll, pitch, dan yaw.

Roll didefinisikan sebagai perputaran pada sumbu longitudinal, yaitu sumbu yang melalui bagian belakang ke bagian depan quadrotor. Perputaran sumbu ini mengakibatkan quadrotor melenggok kekiri atau kekanan. Hal ini diperoleh dengan meningkatkan dorongan (thrust) pada salah satu motor yang terpasang pada sumbu $Y$ dan mempertahankan atau mengurangi dorongan pada motor yang satunya sedangkan dua motor pada sumbu $X$ kecepatan putarannya tetap dipertahankan.

Pitch didefinisikan sebagai perputaran pada sumbu lateral, yaitu sumbu yang melalui bagian kiri ke bagian kanan quadrotor. Perputaran sumbu ini menyebabkan quadrotor mengangguk keatas atau kebawah. Hal ini diperoleh dengan meningkatkan dorongan (thrust) pada salah satu motor yang terpasang pada sumbu $X$ dan mempertahankan atau mengurangi dorongan pada motor yang satunya sedangkan dua motor pada sumbu $Y$ kecepatan putarannya tetap dipertahankan.

Yaw didefinisikan sebagai perputaran pada sumbu vertikal yang tegak lurus terhadap lengan-lengan quadrotor pada titik pusat gravitasi quadrotor. Perputaran pada sumbu ini menyebabkan quadrotor bergerak kesisi kanan atau kesisi kiri. Yaw diperoleh dengan meningkatkan putaran motor-motor pada sumbu $X$ dibandingkan dengan motormotor pada sumbu $Y$ ataupun sebaliknya. Hal ini mengakibatkan quadrotor berputar pada sumbu Z. (Pancev, 2013)

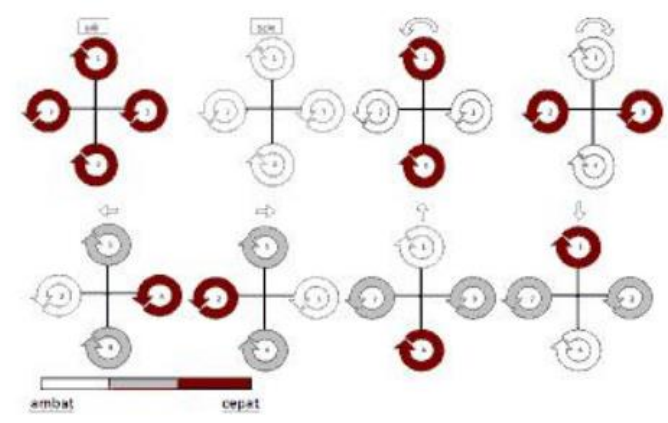

Gambar 2. Pergerakkan dari quadcopter (Andika, 2012)

Gambar 2 menunjukkan bahwa 
quadcopter memiliki 6 dinamika gerak dasar yang dihasilkan dari 4 buah motor yang dikontrol sesuai dengan program yang telah dibuat, sehingga quadcopter tersebut dapat bergerak maju, mundur, belok kiri, belok kanan, memutar kekiri dan kekanan.

Komponen yang diperlukan untuk membuat quadcopter yaitu : frame, motor brushless, electronic speed control (ESC), propeller (baling-baling), bettery Li-Po (3 cell) dan Arduino UNO.

Frame quad X525 merupakan frame yang berukuran diameter $525 \mathrm{~mm}$. Frame ini terbuat dari bahan carbon fiber dan aluminium agar tidak terlalu berat dan lebih kuat. Bentuk frame terlihat pada Gambar 3.

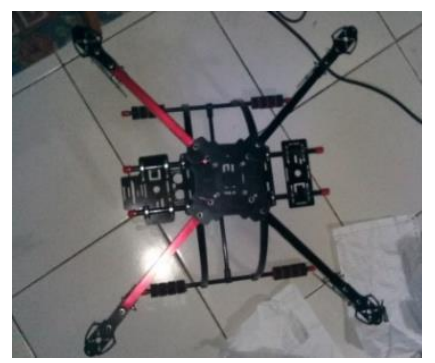

Gambar 3. Frame X525

Battery LiPo (Lithium Polymer) adalah salah satu jenis baterai rechargeable yang sering digunakan pada RC pesawat dan helicopter. Baterai LiPo memiliki tiga keuntungan utama dibandingkan dengan jenis baterai lain seperti $\mathrm{NiMH}$ dan $\mathrm{NiCd}$, yaitu :

1. Ukuran yang lebih kecil dan ringan

2. Memiliki kapasitas yang besar

3. Mampu men-discharge arus yang besar (umumnya untuk supply motor)

Electronic Speed Control (ESC) yang digunakan adalah berjenis brushless, terdiri atas susunan MOSFET (Metal Oxide Semiconductor Field Effect Transistor) untuk mengendalikan kecepatan motor brushless. Electronic Speed Control (ESC) bekerja secara cepat untuk menghidupkan atau mematikan pulsa ke motor, sehingga respon kedali motor cepat. Selain itu Electronic Speed Control (ESC) yang digunakan berbasis mikroprosessor, sehingga dapat deprogram sesuai dengan kebutuhan. Berikut ini adalah gambar dan spesifikasi Electronic Speed Control (ESC) yang digunakan. Untuk lebih jelasnya mengenai Electronic Speed Control (ESC) Gambar 4. Electronic Speed Control (ESC) memberikan catuan pada motor sesuai dengan sinyal Pulse Width
Modulation (PWM) yang masuk pada input ESC.

Motor brushless direct current (BLDC) adalah motor yang tidak menggunakan sikat atau brush untuk pergantian medan magnet (komutasi) tetapi dilakukkan secara komutasi elektronis.

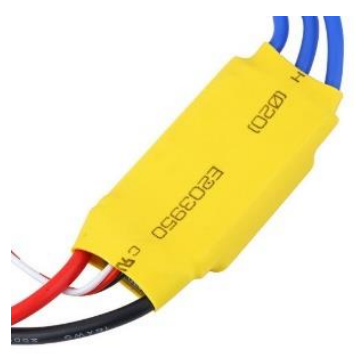

Gambar 4. Electronic Speed Control (ESC) (Prawirayuda, F., 2012)

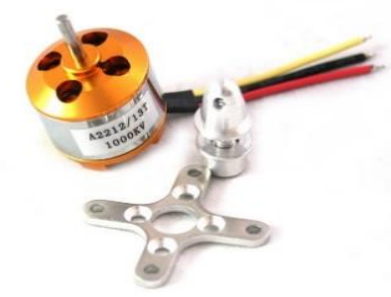

Gambar 5. Motor Brushless (Nurmansyah. 2014)

Gambar 5 merupakan tampilan dari motor brushless. Motor DC magnet permanen (DC-MP) dengan motor brushless DC berbeda. Perbedaannya terletak pada pembangkitan medan magnet untuk menghasilkan gaya gerak. Jika pada motor DC-MP medan magnet yang dikontrol berada di rotor dan medan magnet tetap berada di stator. Sebaliknya, motor brushless menggunakan pembangkitan medan magnet stator untuk mengontrol geraknya sedangkan medan magnet tetap berada di rotor.

Baling-baling (propeller) adalah alat untuk menjalankan pesawat terbang. Balingbaling ini memindahkan tenaga dengan mengkonversi gerakan rotasi menjadi daya dorong untuk menggerakkan sebuah kendaraan seperti pesawat terbang, untuk melalui suatu massa seperti udara, dengan memutar dua atau lebih bilah kembar dari sebuah poros utama, seperti yang terlihat pada Gambar 6 .

Sensor IMU MPU6050 merupakan salah satu produk sensor MEMS Motion Tracking yang diproduksi oleh perusahaan Invensense. MPU6050 merupakan sebuah IC yang terdiri dari accelerometer dan gyroscope 
digital yang masing-masing memiliki orientasi 3 axis terlihat pada Gambar 7. Baik accelerometer maupun gyroscope yang ada pada MPU6050 memiliki 16 bit output digital yang bisa diakses melalui jalur antarmuka I2C atau SPI.

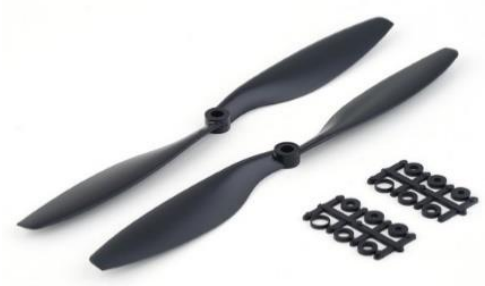

Gambar 6. Propeller 10x4.5 inch CW dan CCW. (Dharmawan, A., 2012)

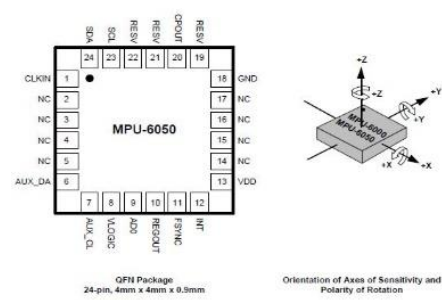

Gambar 7. Sensor IMU MPU6050 (IvenSense, 2013)

Sensor Ultrasonic HC-SRO4 adalah sebuah sensor yang berfungsi untuk mengubah besaran fisis (bunyi) menjadi besaran listrik dan sebaliknya. Cara kerja sensor ini didasarkan pada prinsip dari pantulan suatu gelombang suara sehingga dapat dipakai untuk menafsirkan eksistensi (jarak) suatu benda dengan frekuensi tertentu. Disebut sebagai sensor ultrasonik karena sensor ini menggunakan gelombang ultrasonik (bunyi ultrasonik).

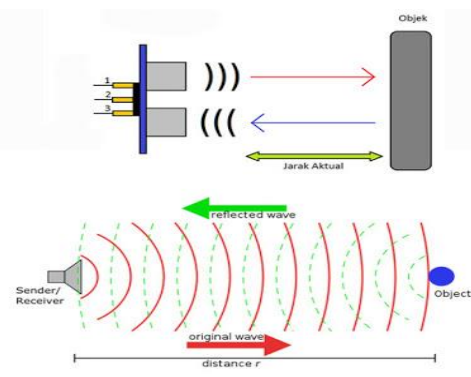

Gambar 8. Sensor Ultrasonic HC-SR04 (ElecFreaks, 2016)
Arduino Uno terdiri dari kata " Uno " berasal dari bahasa Italia yang berarti "satu", dan dipilih untuk menandai peluncuran Software Arduino (IDE) versi 1.0. Arduino. Sejak awal peluncuran hingga sekarang, Uno telah berkembang menjadi versi Revisi 3 atau biasa ditulis REV 3 atau R3. Software Arduino IDE, yang bisa diinstall di Windows maupun Mac dan Linux, berfungsi sebagai software yang membantu anda memasukkan (upload) program ke chip ATMega328 dengan mudah.

Arduino Uno memiliki 14 digital pin input / output (atau biasa ditulis I/O, dimana 6 pin diantaranya dapat digunakan sebagai output PWM), 6 pin input analog, menggunakan crystal $16 \mathrm{MHz}$, koneksi USB, jack listrik, header ICSP dan tombol reset. Pin digital memiliki dua buah nilai yang dapat ditulis kepadanya yaitu High(1) dan Low(0). Logika high maksudnya ialah 5 Volt dikirim ke pin baik itu oleh mikrokontroler atau dari komponen. Low berarti pin tersebut bertegangan 0 Volt. Dari logika ini, anda dapat membayangkan perumpamaan: start/stop, siap/tidak siap, on/off, dsb.

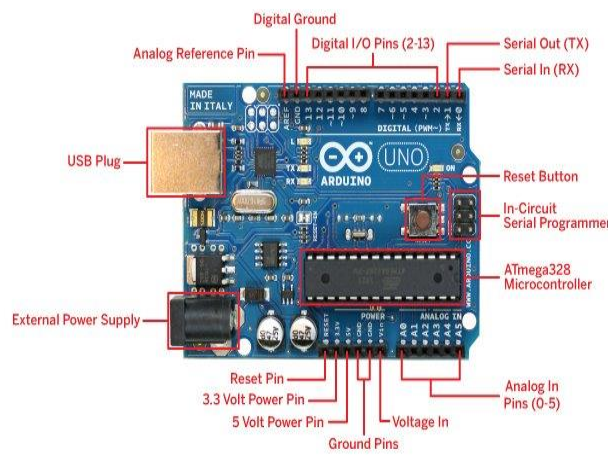

Gambar 9. Arduino Uno (Ecadio, 2016)

Gambar 9 menunjukkan pin-pin digital berada pada bagian atas. Pin-pin itulah yang nantinya dihubungkan ke berbagai kontrol yang berkomunikasi dengan menggunakan nilai digital. Beberapa pin digital dapat digunakan sebagai Pulse Width Modulation(PWM). Secara umum pin PWM ini dapat digunakan untuk mengirim nilai/informasi analog ke komponen. Tanda pada pin 3, 5, 6, 9, 10, 11 menandakan fungsi PWM.

Aksi kontrol PID (Proportional, Integral, Derivative) banyak ditemukan di dunia industri dan satu-satunya strategi yang paling banyak diadopsi pada pengontrolan proses. Berdasarkan survei, $97 \%$ industri yang 
bergerak dalam bidang proses (seperti kimia, pulp, makanan, minyak, dan gas) menggunakan PID sebagai komponen utama dalam pengontrolannya. PID (dari singkatan bahasa Inggris: Proportional-IntegralDerivative controller) merupakan kontroler untuk menentukan presisi suatu sistem instrumentasi dengan karakteristik adanya umpan balik pada sistem tersebut. Komponen kontrol PID ini terdiri dari tiga jenis yaitu Proportional, Integral dan Derivative.

\section{METODE PERANCANGAN}

Perancangan berfokus pada kendali posisi ketinggian quadcopter. Sistem kendali yang merupakan hubungan antara komponen yang membentuk sebuah konfigurasi sistem, untuk menghasil-kan tanggapan sistem yang diharapkan. Jadi harus ada yang dikendalikan, yang merupakan suatu fisis, yang biasa disebut dengan kendalian (plant) Gambar 10.

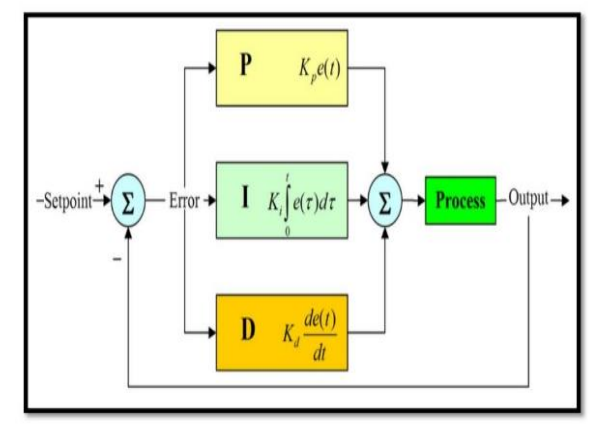

Gambar 10. Blok diagram PID Controller (Domingues, 2009)

Rancangan kendali posisi dan ketinggian quadcopter digunakan untuk mengendalikan quadcopter dengan menggunakan metode kendali PID (PID Controller) berfungsi untuk melakukkan proses kendali quadcopter pada posisi ketinggian tertentu sesuai dengan setpoint yang diberikan. Set-point yang dimaksud adalah nilai ketinggian terbang yang harus dicapai oleh quadcopter dan bertahan pada posisi tersebut.

Perancangan pengendali menggunakan komunikasi serial yang berfungsi untuk mengirim data instruksi ke perangkat kendalian (plant) pada quadcopter. Sensor ultrasonic untuk mendeteksi posisi dan ketinggian yang dicapai quadcopter, kemudian mengirimkan sinyal hasil respon melalui media komunikasi untuk diteruskan ke komputer sebagai monitoring hasil respon dalam bentuk grafik.

Pada gambar 11, Arduino Uno R3 digunakan sebagai system utama yang memegang kendali atas semua system yang berjalan. Semua perangkat seperti sensor IMU MPU6050, Sensor Ultrasonic HC-SR04, Receiver, ESC (Electronic Speed Control) terhubung ke system utama.

Sensor IMU MPU6050 memiliki 16 bit output digital yang bisa diakses melalui jalur antar muka I2C atau SPI. Receiver yang terhubung ke pin Arduino Uno R3 yang kemudian pin-pin tersebut menjadi keluaran dari receiver. Electronic Speed Control (ESC) memiliki saluran data sinyal yang terhubung ke pin pada Arduino Uno R3 sebagai keluaran dari pemrosesean data sinyal pada system yang dilanjutkan oleh ESC tersebut ke motor brushless sehingga motor brushless dapat dikontrol kecepatannya.

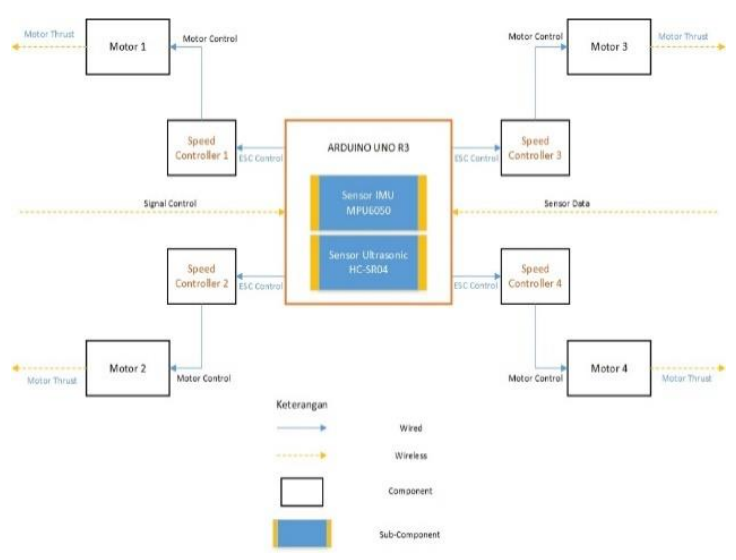

Gambar 11. Blok diagram sistem

Quadcopter model merupakan komponen yang menjadi bagian utama sebagai plant yang akan dikendalikan dalam sistem yang akan dirancang.

Spesifikasi quadcopter model yang digunakan adalah jenis cross $(\mathrm{X})$ dengan frame berdasar dari alumunium dan penyangga tengah frame terbuat dari carbon fyber. Bahan dasar tersebut yang menjadikan quadcopter model ini lebih ringan dalam terbang dari pada pesawat model dengan bahan yang lain.

Mekanika quadcopter terlihat pada Gambar 12 dan Gambar 13 Quadcopter yang akan dirancang terdapat empat motor brushless yang berfungsi sebagai aktuator. Untuk mengatur kecepatan dari motor brushless tersebut digunakan Electronic Speed Control (ESC). Quadcopter juga dilengkapi dengan sensor IMU MPU6050 yang merupakan sensor yang berfungsi untuk 
menghitung percepatan serta orientasi arah pergerakan dari kendaraan udara dengan menggunakan kombinasi dari sensor accelerometer dan gyroscope.

Dengan adanya IMU, kendaraan udara bisa menghitung dan mengetahui pergerakan yang dilakukannya, sehingga dapat membantu kendaraan tersebut untuk mengetahui posisi serta lintasan yang dilaluinya tanpa menggunakan GPS (misalkan ketika tidak mendapatkan sinyal GPS).

IMU bekerja dengan menggunakan tiga sensor accelerometer yang digunakan untuk menghitung percepatan di sumbu $x, y$, dan $z$. Nantinya, accelerometer akan dipadukan dengan gyroscope untuk menentukan arah mana yang sedang diambil oleh quadcopter ketika melakukan percepatan tersebut dan dengan mencatat serta menggabungkan semua perhitungan tersebut, akan didapatkan posisi baru dari quadcopter yang bergerak, serta jalur pergerakan yang diambilnya. Penempatan sensor IMU MPU6050 ini tepat berada dititik tengah dari frame quadcopter.

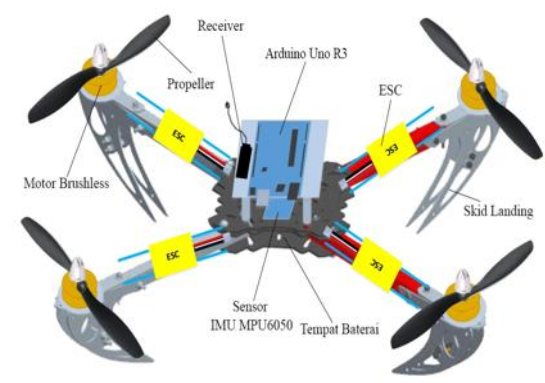

Gambar 12. Desain quadcopter.

Skema rangkaian Quadcopter seperti pada Gambar 14 memperlihatkan beberapa komponen lain yang terhubung seperti resistor, diode, dan LED. Dari rangkaian tersebut baterai yang di hubungkan ke resistor yang kemudian di sambungkan VCC (5V) pada arduino, di antara R2 dan R3 dihubungkan ke pin $\mathrm{A} 0$ yang berfungsi untuk mengetahui power dari baterai. Ketika baterai lemah, LED yang dihubungkan ke pin D12 akan berkedip-kedip yang bertanda baterai dalam keadalan lemah. Untuk sinyal informasi keempat ESC (Electronic Speed Control) masing-masing terhubung ke PORTD pin (4,5,6 dan 7).

Sedangkan untuk sensor IMU MPU6050 pin yang terhubung ke SDA dan SCL pada pin sensor IMU MPU6050 ialah pin A4 dan A5 atau (SDA dan SCL) pada arduino. Pin D8 inputan roll (left and right), pin D9 inputan pitch (nose up and nose down), pin
D10 inputan throttle (up and down), dan pin D10 inputan yaw (nose left and nose right) pada receiver.

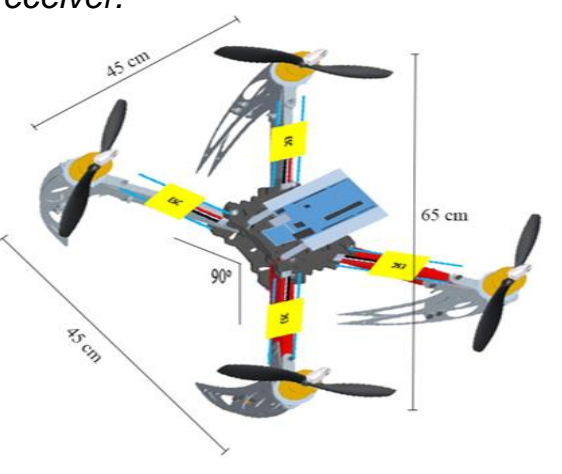

Gambar 13. Dimensi quadcopter.

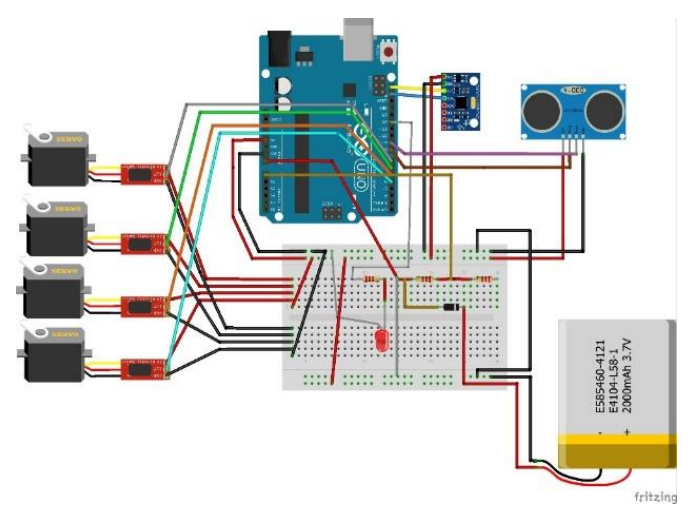

Gambar 14. Rangkaian Skematik Quadcopter

\section{HASIL DAN PEMBAHASAN}

Pada Gambar 15 dapat dilihat lima komponen penyusun sistem quadcopter. Komponen tersebut antara lain Motor Brushless, Propeller, ESC (Electronic Speed Control), baterai quadcopter sebagai sumber daya sistem keseluruhan quadcopter. Untuk lebih detailnya, baterai quadcopter dan sensor ultrasonic dapat diperlihatkan pada Gambar 16. Baterai quadcopter yang ditempatkan pada bagian bawah quadcopter. Jenis baterai yang digunakan adalah LiPo (Lithium Polymer) 3S 11.1 Volt dengan kapasitas 2200 mAh. Pada Gambar 17 juga terlihat sensor ultrasonic berfungsi untuk menahan posisi ketinggian.

Pengujian nilai sensor ultrasonic untuk menahan posisi ketinggian quadcopter ini dilakukkan dengan meletakkan quadcopter di tempat lepas landas kemudian quadcopter di angkat sesuai dengan ketinggian yang telah ditentukan untuk mengetahui seberapa sensitifitas pembacaan nilai sensor ultrasonic pada quadcpter tersebut. Pengambilan nilai sensor dilakukkan sebanyak 9 kali dengan sampel data masing-masing satu kali 
pengujian 30 nilai sampel seperti gambar 18 .

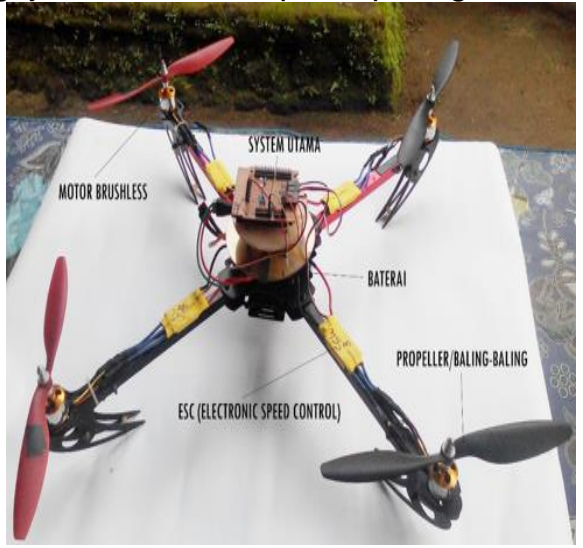

Gambar 15. Tampilan luar quadcopter.

Pengujian nilai sensor ultrasonic bertujuan untuk melihat sesistifitas dari sensor ultrasonic dalam membaca jarak. Pengujian dilakukan menggunakan sensor Atmega 328P dengan senosor ultrasonic HC-SR04 dengan frequency $20-40 \mathrm{KHz}$ dan tegangan $\mathrm{DC} 5 \mathrm{~V}$. Nilai yang didapat tersebut dapat di cari menggunakan persamaan $\mathrm{S}=340 \times \mathrm{t} / 2$.

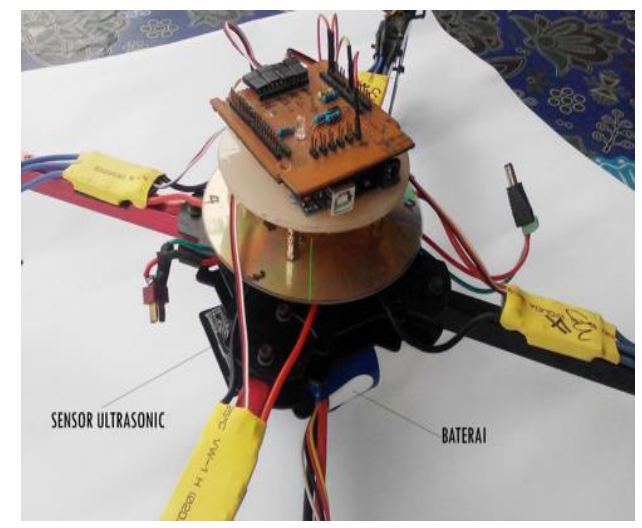

Gambar 16. Baterai dan sensor ultrasonic HC-SR04.

Gambar 19 bagian (a) merupakan proses penstabilan propeller. Proses penstabilan ini dilakukkan dengan menggerakan motor brushless dengan kecepatan putaran 1000 - 1600 us. Apabila getaran pada motor brushless semakin tinggi ketika putaran motor brushless semakin cepat itu menandakan bahwa propeller belum stabil. Untuk menstabilkan propeller digunakan cara manual yaitu dengan menempelkan sebuah isolasi/isolator pada bagian atas dari propeller terlihat pada gambar 20 bagian (b). Hal ini dilakukkan berulang-ulang sampai getar pada motor brushless berkurang atau hilang sehingga tidak mempengaruhi kesetabilan quadcopter ketika lepas landas.

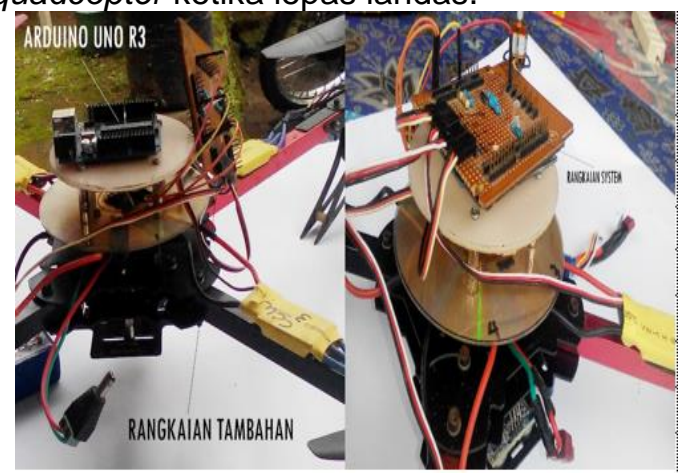

Gambar 17.Sistem pendukung quadcopter.

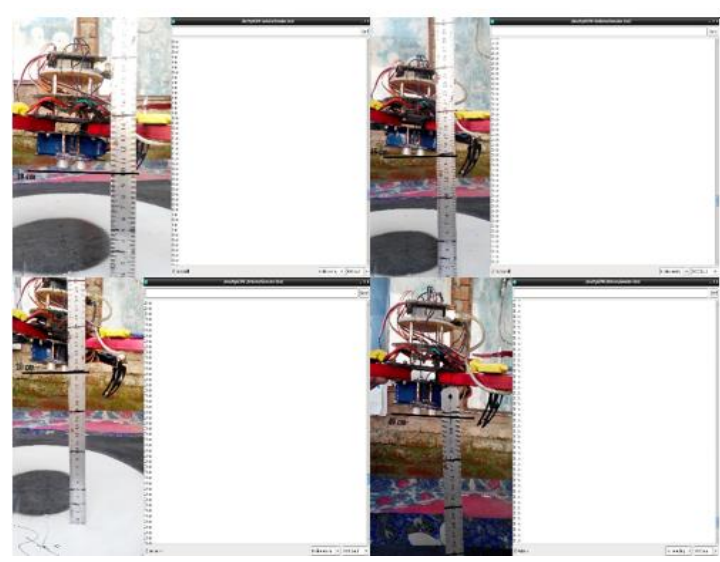

Gambar 18. Pengujian sensor ultrasonic HC-SR04.

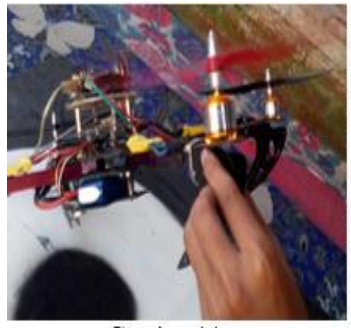

Gambar (a)

Proses balancing propeller

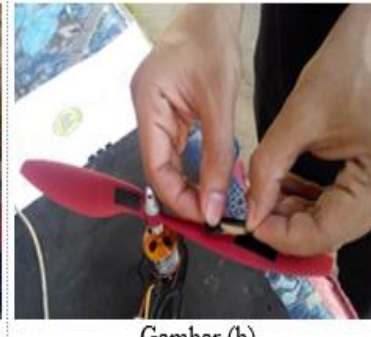

Gambar (b)

Penambahan beban pada propeller
Gambar 19. Pengujian putaran baling-baling (propeller).

Pada Gambar 20 merupakan proses pengambilan data sudut pitch pada quadcopter. Pada gambar tersebut pengambilan data dilakukkan dengan meletakkan quadcopter di tempat yang datar agar sudut 0 derajat pada quadcopter dapat terbaca. Proses pengambilan data sudut kemiringan ini dilakukkan dengan pengujian sebanyak 8 kali dengan pengujian sudut yang berbeda-beda. 
Pengujian dan pengambilan data sensor untuk sudut roll juga dilakukkan sama seperti saat pengambilan data sudut pitch di atas. Hal ini terlihat pada Gambar 21.

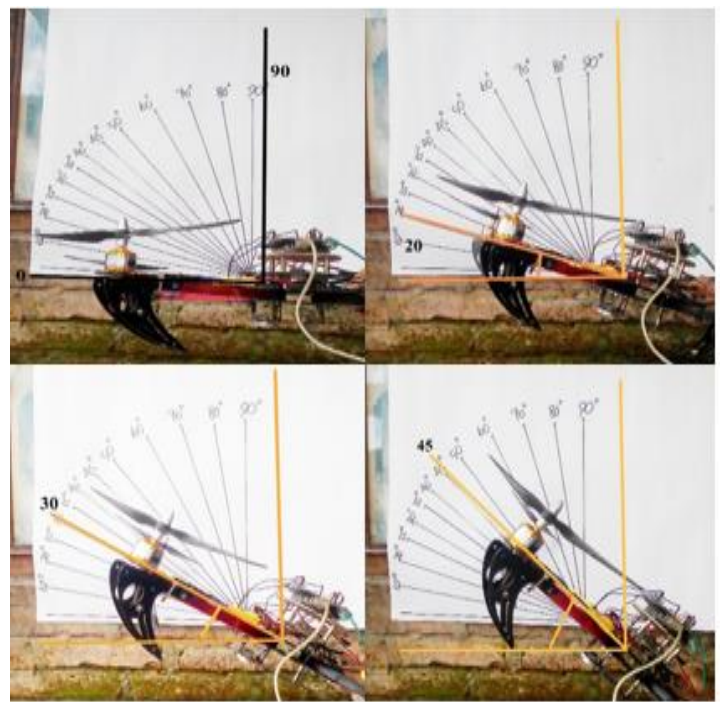

Gambar 20. Pengambilan data sudut pitch.

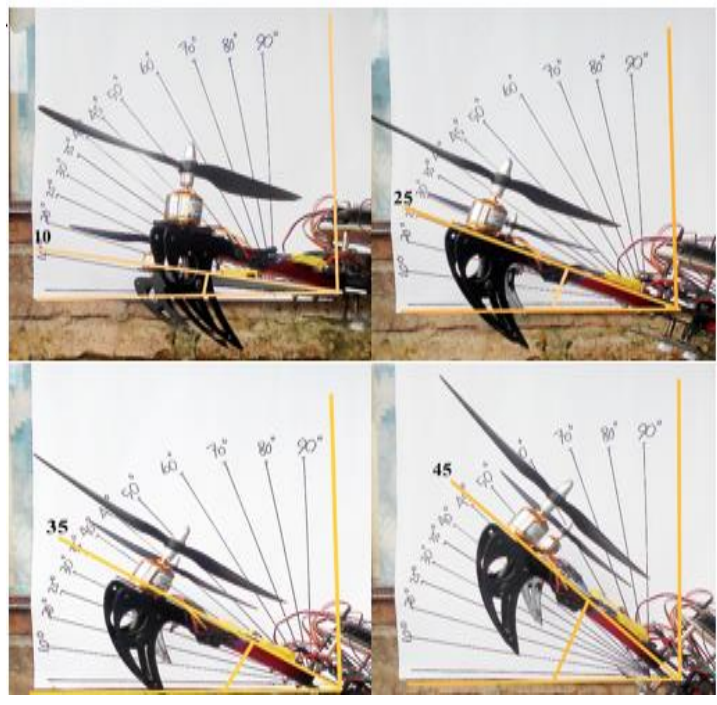

Gambar 21. Pengambilan data sudut roll.

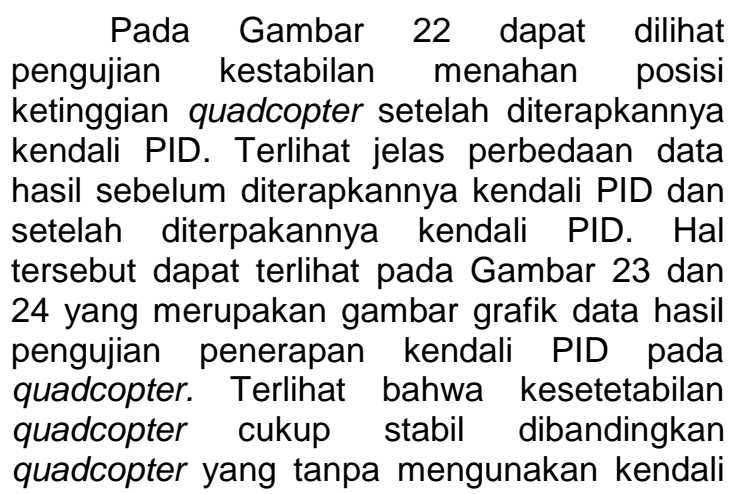

PID.

Pengujian ini diberikan pengaturan kendali PID pada roll, pitch, yaw dan sensor ultrasonic. Dalam hal ini pengaturan untuk roll dan pitch dengan nilai $\mathrm{P}=1.4, \mathrm{I}=0.012, \mathrm{D}=$ 13.7. Untuk yaw diberikan nilai $P=3.0, I=$ $0.02, \mathrm{D}=0$. Kemudian untuk ketinggian diberikan nilai $P=19.0, I=0.2, D=8.3$. Pengaturan tersebut didapaatkan dengan melakukan pengujian secara manual pada quadcopter

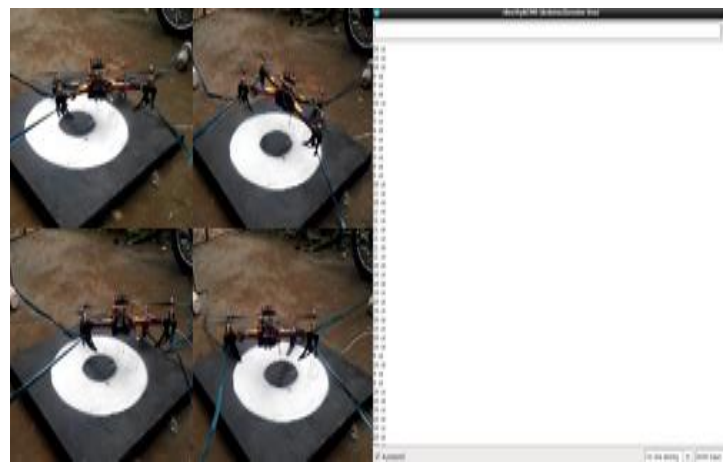

Gambar 22. Pengujian kesetabilan quadcopter tanpa kendali PID.

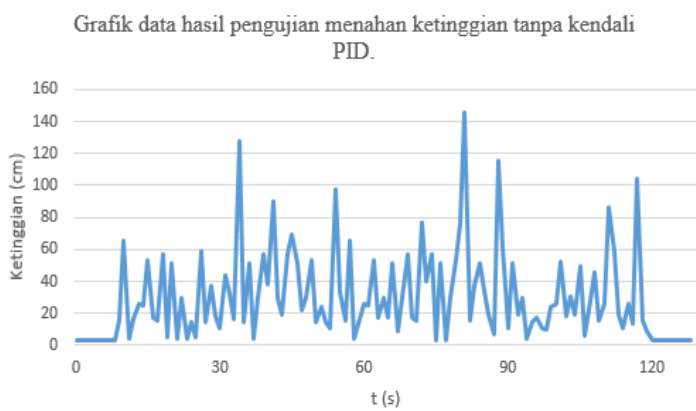

Gambar 23. Grafik data hasil pengujian kestabilan quadcopter tanpa kendali PID.

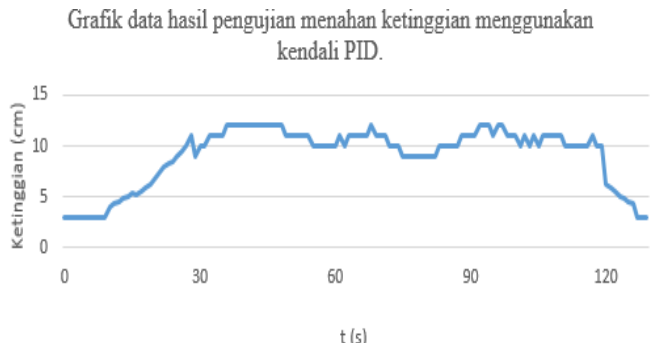

Gambar 24. Grafik data hasil pengujian kestabilan quadcopter menggunakan kendali PID.

Pengujian tingkat keberhasilan sistem quadcopter dilakukan dengan memberikanketinggian permukaan landing yang berbeda-beda. Pengujian ini bertujuan 
untuk mengetahui sistem yang diterapkan pada quadcopter ini berhasil atau tidak. Proses pengujian tahap akhir ini dilakukkan dengan cara 2 cara yang pertama memberikan posisi ketinggian berbeda-beda pada quadcopter dengan permukaan landing yang sama kemudian yang kedua memberikan posisi ketinggian yang sama pada quadcopter namun ketinggian landing yang berbeda.

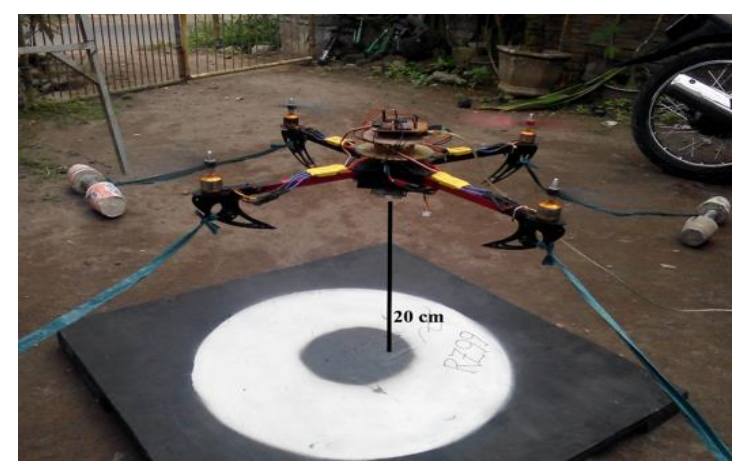

Gambar 25. Pengujian keberhasilan sistem dengan posisi ketinggian $20 \mathrm{~cm}$.

Pengujian yang pertama quadcopter diberikan posisi ketinggian $20 \mathrm{~cm}$, dan $20 \mathrm{~cm}$ untuk mampu menahan posisi ketinggian sesuai dengan set point yang diberikan. Pengujian tersebut terlihat pada Gambar 25 pada gambar tersebut diberikan set point 20 $\mathrm{cm}$ sehingga didapatkan data hasil pengujian yang terlihat pada Gambar 26.

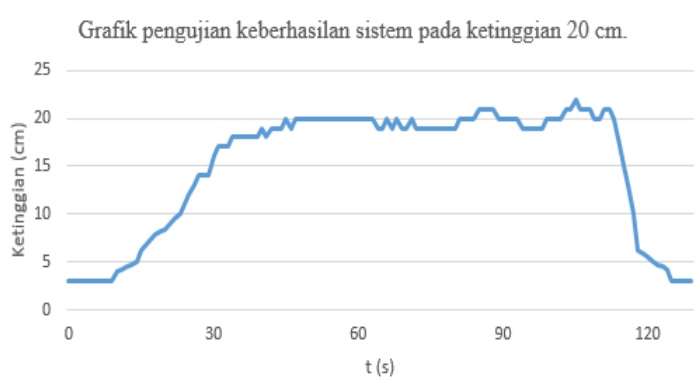

Gambar 26 Grafik data hasil pengujian keberhasilan sistem dengan posisi ketinggian 20 $\mathrm{cm}$.

Pada pengujian kedua quadcopter diberikan posisi ketinggian sama yaitu $30 \mathrm{~cm}$ yang bertujuan untuk mengetahui quadcopter mampu menahan posisi ketinggian tersebut dengan permukaan landing yang berbeda.

Pada Gambar 27 terlihat quadcopter diberikan set point ketinggian $30 \mathrm{~cm}$ dan didapatkan data hasil dalam bentuk grafik pada Gambar 28 Pada grafik tersebut terlihat quadcopter cukup mampu menahan posisi ketinggian dengan setpoint yang diberikan namun tidak sestabil pada posisi keitinggian $20 \mathrm{~cm}$.

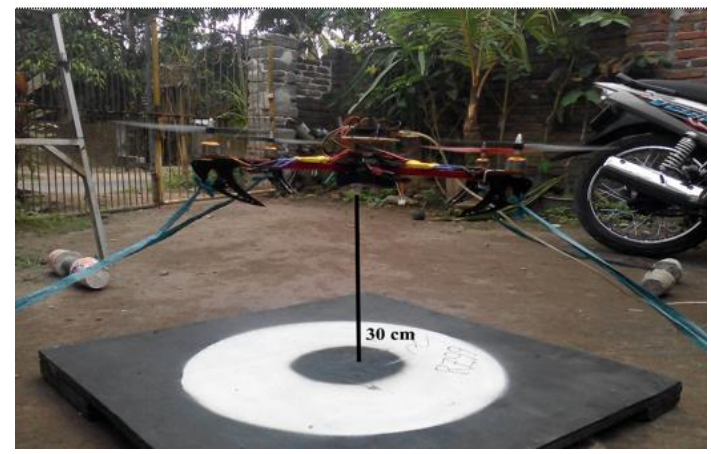

Gambar 27. Pengujian keberhasilan sistem dengan posisi ketinggian $30 \mathrm{~cm}$.

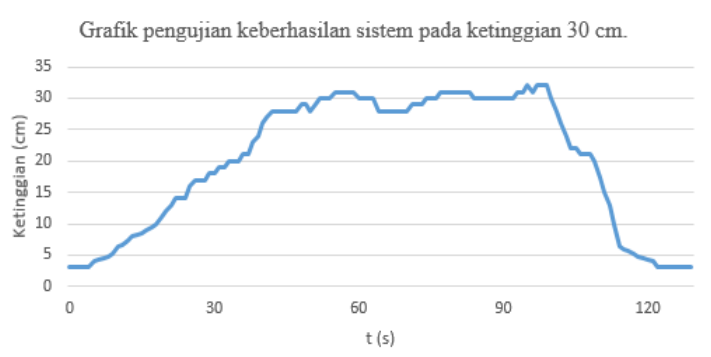

Gambar 28. Grafik data hasil pengujian keberhasilan sistem dengan posisi ketinggian 30 $\mathrm{cm}$.

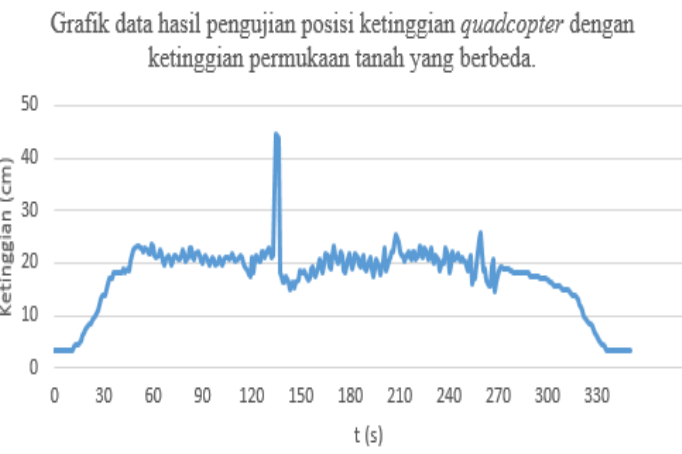

Gambar 29 Grafik data hasil pengujian keberhasilan sistem posisi ketinggian $20 \mathrm{~cm}$ dengan permukaan landing berbeda.

Pada grafik Gambar 29 dapat dilihat bahwa ketika quadcopter diberikan posisi ketinggian $20 \mathrm{~cm}$ di atas permukaan meja yang tingginya $20 \mathrm{~cm}$ juga quadcopter cukup mampu bertahan meskipun tidak cukup stabil kemudian meja ditarik sehingga quadcopter turun ke bawah untuk mencari posisi ketinggian $20 \mathrm{~cm}$ dari permukaan yang dibaca terlihat pada Grafik 27. nilai kestabilan pada 
quadcopter menurun beberapa detik namun mulai cukup stabil beberapa detik kemudian.

\section{KESIMPULAN}

Dari proses pembuatan quadcopter dengan menahan posisi ketinggian yang menggunakan sensor jarak ultrasonic $\mathrm{HC}$ SR04 dengan kendali PID, mulai dari proses perancangan perangkat keras, perangkat lunak, hingga pengambilan data, dapat ditarik beberapa kesimpulan sebagai berikut :

1. Sistem quadcopter yang dibuat telah dapat menahan posisi ketinggian tertentu sesuai setpoint yang diberikan.

2. Dalam menahan posisi ketinggian $10 \mathrm{~cm}$ memiliki persentasi error $4.2 \%$ dan $20 \mathrm{~cm}$ memiliki persentase error $2.9 \%$, sedagkan untuk ketinggian $30 \mathrm{~cm}$ memiliki persentase error $3.2 \%$. Dari ketiga posisi ketinggian tersebut quadcopter mampu menahan posisi ketinggian dengan persentase error kecil pada masing - masing ketinggian.

3. Untuk kesetabilan sistem digunakan kendali PID. Dalam hal ini kendali PID di setting dengan $\mathrm{P}=3.0, \mathrm{I}=0.02, \mathrm{D}=0$ untuk setting-an ketinggian. Untuk setting-an pitch dan roll diberikan nilai gain $\mathrm{P}=1.4, \mathrm{I}=0.012, \mathrm{D}=13.7$. Sedangkan untuk yaw diberikan nilai gain $P=19.0, I=0.2, D=8.3$. Sehingga quadcpter cukup stabil.

\section{DAFTAR PUSTAKA}

Andika, F., 2012. Perancangan dan Implementasi Autonomous Landing Menggunakan Behavior-Based dan Fuzzy Controller pada Quadcopter, Jurnal Teknik ITS vol.1 No.1

Dharmawan, A., dan Firdaus, N.I., 2012, Purwarupa Sistem Otomasi Terbang
Landas dan Mendarat Quadcopter, IJEIS, Vol.2, No.1, April 2012, pp. 8796, ISSN : 2088-3714

Domingues, and Jorge M.B., 2009, Quadrotor Prototype, Master's thesis., Intituto Superior Tecnico Lisboa.

Ecadio, 2016, Belajar dan Mengenal Arduino Uno, tersedia di www.ecadio.com, diakses tanggal 20 Oktober 2016.

Elec-Freaks, 2016, HC-SR04 User Guide, tersedia di www.elecfreaks.com, diakses pada tanggal 20 Oktober 2016.

IvenSense, 2013, MPU-6000 and MPU-6050 Product Specification Revision 3.4, tersedia di www.ivensense.com, diakses pada tanggal 07 September 2016.

Nurmansyah, 2014, Kontrol Kesetabilan Quadcopter dengan Menggunakan Sensor Gyroscope ITG 3205, Jurnal Politeknik Negri Sriwijaya, Palembang.

Pancev, I.G.D., Swamardika, I.B.A., Budiastra., I.N., 2013, Implementasi Penggunaan Sensor Accelerometer ADXL335 Pada Quadcopter Robot Berbasis ATMega32, Jurusan Teknik Elektro, Fakultas Teknik, Universitas Udayana

Prawirayuda, F., Astrowulan, K.A.K., Efendhie, R., 2012, Desain dan Implementasi Kontroler Fuzzy-Model Reference Adaptive Control (FuzzyMRAC) untuk Proses Take-off pada Unmanned Aerial Vehicle (UAV) Quadcopter, Jurnal Teknik Pomits Vol. 1, No. 1, (2012) 